\title{
Brief Probe into the Key Factors that Influence Beijing Agricultural Drought Vulnerability
}

\author{
Lingmiao Huang, Peiling Yang, and Shumei Ren \\ College of Water Resources \& Civil Engineering, China Agricultural University, \\ Beijing 100083, China \\ huanglingmiao@cau.edu.cn, \{yangpeiling,renshumei\}@126.com
}

\begin{abstract}
Drought is a major disaster that Beijing agricultural systems faced with. The risk of drought disasters is a result of drought disaster together with vulnerability, the result of drought disaster only appeared in post-disaster, before the disaster occurred, we need to make some research on drought vulnerability that Beijing agricultural systems faced with, we choose VAM (vulnerability assessment method) that consist of three drought elements: exposure, sensitivity and adaptive capacity, based on two kinds of analytic hierarchy process method to determine the weight of each factors. try to verify the results of agricultural drought indicator system through the spatial distribution map of soil moisture, as well as explore the key factors that influence Beijing agricultural drought vulnerability.
\end{abstract}

Keywords: Vulnerability, Assessment, Indicator System, Analytic Hierarchy Process, Agricultural Drought, Soil Moisture.

\section{Introduction}

Vulnerability is context-specific and what makes one region or community vulnerable may be different from another community [1]. The main Vulnerability research bodies are diverse, such as ecosystem, the forests [2] and wetlands [3], etc. ;water resources system [4]; human-environment system [5], urban social living system [6], there are more widely agricultural system [7-11], etc.; current research also focus on vulnerability caused by climate change [6, 12-15]; as well as vulnerability studies on earthquake disasters [16], flood disasters [17-20] and caused by land use changes [21], etc.

The risk of natural disasters is a result of natural disasters together with vulnerability, the level of loss risk is directly related with social vulnerability, to a great extent, decided by the vulnerability of hazard bearing [22]. However, there are certain generic determinants of vulnerability including developmental factors that are likely to influence the vulnerability of a particular region or community even in diverse socioeconomic contexts [1]. Thus, one of the key features of vulnerability is its dynamic nature that may change as a result of changes in the biophysical as well as the socioeconomic characteristics of a particular region [23]. Hence, vulnerability assessments should be ongoing processes in order to highlight the spatial and temporal scales of vulnerability of a region [24]. 
This paper focuses on agricultural drought vulnerability which means the property or status which is sensitive to drought and easily threatens by drought, as well as caused loss [25]. The impact factors of drought vulnerability are multifaceted [26], meanwhile, vulnerability studies combined tightly with spatial scales [27]. Some scholars have tried a variety of methods to evaluate the overall vulnerability of agricultural drought; they appropriately selected the indicators mainly based on the main bodies and scales in evaluation and assessment [8, 9, and 28]. Currently, researches focused on choosing two or three factors from the three factorsexposure, sensitivity and adaptability to determine the indicators [10, 29, and 30].

The aim of this paper is to develop and apply a quantitative approach to agricultural drought vulnerability assessment within Beijing to identify which of the country's regions and districts are most vulnerable to drought, also use a method to test the assessment results. To achieve this aim, the study objectives are:

1. To establish an indicator system for the assessment of agricultural drought based on the three elements of drought vulnerability;

2. To select 15 factors represent drought exposure, sensitivity and adaptive capacity, based on two kinds of analytic hierarchy process method to evaluate the exposure, adaptive capacity and sensitivity of Beijing's eleven regions and the districts within the most vulnerable regions;

3. To verify the results of agricultural drought indicator system through the spatial distribution map of soil moisture.

4. To explore the key factors that influence Beijing agricultural drought vulnerability.

\section{Materials and Methods}

\subsection{Study Area}

Beijing is located in the longitude of $115^{\circ} 20^{\prime}$ to $117^{\circ} 30^{\prime}$ and the latitude of $39^{\circ} 25^{\prime}$ to $41^{\circ}$. About $150 \mathrm{~km}$ distance to the west of Bohai, located in the northwest edge of the North China Plain, the city's total area is $16410.54 \mathrm{~km}^{2}$, mountain area account for $62 \%$, and about $38 \%$ of the areas are plains.

The growth period of winter wheat in Beijing start from late September to midJune, the rainfall of Beijing area is generally concentrated in the June to August, appear the phenomenon of precipitation and growth period of winter wheat water requirement dislocation, drought is a direct threat to stable and high yield of winter wheat, even has a serious impact on the socio-economic. It is urgent to carry out the study on Beijing drought vulnerability and reduce drought disasters.

\subsection{Research Method}

In this paper, using VAM vulnerability assessment methods [11], the three elements of vulnerability classified as exposure, sensitivity, and adaptive capacity. Exposure represent that system experience a degree of drought stress, it is related to the intensity, frequency and duration of the drought; sensitivity is the extent of agricultural system elements susceptible to the effects of drought; adaptive capacity is the behavior that stakeholders in the agricultural system taking to reduce the effects of 
drought in the pre-disaster and after disaster. The results of exposure, sensitivity, and adaptive capacity Co-expressed as drought vulnerability.

Using the formula [11]

$$
V=f(E, S, A)
$$

By the composite indicator method, the vulnerability results can be expressed as various indicators and the linear plus of their corresponding weights:

$$
\mathrm{V}=\sum_{\mathrm{i}=1}^{\mathrm{n}} \mathrm{I}_{\mathrm{i}} \times \mathrm{w}_{\mathrm{i}}+\sum_{\mathrm{l}=1}^{\mathrm{m}} \mathrm{I}_{\mathrm{l}} \times \mathrm{w}_{\mathrm{l}}+\sum_{\mathrm{r}=1}^{\mathrm{s}} \mathrm{I}_{\mathrm{r}} \times \mathrm{w}_{\mathrm{r}}
$$

In the formula (1), $\mathrm{V}$ is drought vulnerability indicator of the evaluation unit; $\mathrm{E}$ is drought exposure indicator; $\mathrm{S}$ is drought sensitivity indicator; $\mathrm{A}$ is drought adaptability indicator. There are respectively multiplied by the evaluation indicator scores that belonging to the three elements and the corresponding weight of evaluation indicator. The $\mathrm{I}_{\mathrm{i}} 、 \mathrm{Il}$ 、 $\mathrm{Ir}$ are the score of evaluation indicator $\mathrm{i}, \mathrm{l}, \mathrm{r}$; Wi $\mathrm{Wl}$ 、 Wr are the weight value of the evaluation indicator $i 、 1 、 r$.

\subsubsection{Establishment of the Evaluation Indicator System}

Starting from the three elements: exposure, sensitivity, and adaptive capacity to select representative sub-elements in order to refine the three elements.

\begin{tabular}{|c|c|c|c|c|}
\hline Element & Evaluation indicators & The explain of evaluation indicators & Data sources & Time \\
\hline \multirow{4}{*}{ Exposure (E) } & $\begin{array}{l}\text { Difference value } \\
\text { between evaporation and } \\
\text { rainfall } / \mathrm{mm}(+)\end{array}$ & $\begin{array}{l}\text { Reflects the degree of crop water } \\
\text { demand is satisfied }\end{array}$ & $\begin{array}{l}\text { China Meteorological Data } \\
\text { Sharing Network }\end{array}$ & \multirow{4}{*}{2010} \\
\hline & Average elevation/m(+) & $\begin{array}{l}\text { Elevation is positively related to } \\
\text { water abstraction difficulty during } \\
\text { the drought period }\end{array}$ & \multirow{3}{*}{$\begin{array}{l}\text { International Scientific } \\
\text { Database ( } 90 \text { meter } \\
\text { resolution data) }\end{array}$} & \\
\hline & Average slope $/^{\circ}(+)$ & $\begin{array}{l}\text { The slope affect soil water retention } \\
\text { capacity, increasing the severe } \\
\text { drought period irrigation difficulty }\end{array}$ & & \\
\hline & $\begin{array}{l}\text { The river network } \\
\text { density/ }\left(\mathrm{km} / \mathrm{km}^{2}\right) \quad(-)\end{array}$ & $\begin{array}{l}\text { Lack of precipitation, surface } \\
\text { runoff is a major water sources of } \\
\text { production and living }\end{array}$ & & \\
\hline \multirow{3}{*}{ Sensitivity (S) } & Forest coverage $1 \%(-)$ & $\begin{array}{l}\text { Influence the climate of the area } \\
\text { and the conservation of rainfall }\end{array}$ & \multirow{3}{*}{$\begin{array}{l}\text { Regional Statistical } \\
\text { Yearbook of Beijing }\end{array}$} & \multirow{3}{*}{2010} \\
\hline & The irrigation index (-) & $\begin{array}{l}\text { The proportion of effective } \\
\text { irrigation area in the total area of } \\
\text { cultivated land }\end{array}$ & & \\
\hline & $\begin{array}{l}\text { Winter wheat planting } \\
\text { ratio }(+)\end{array}$ & $\begin{array}{l}\text { The proportion of winter wheat } \\
\text { acreage in the total cultivated area }\end{array}$ & & \\
\hline
\end{tabular}

Table 1. List of drought vulnerability indicators 
Table 1. (continued)

\begin{tabular}{|c|c|c|c|c|}
\hline & $\begin{array}{c}\text { Proportion of agricultural } \\
\text { population }(+)\end{array}$ & \multicolumn{3}{|l|}{$\begin{array}{l}\text { The agricultural population groups } \\
\text { are most sensitive to drought }\end{array}$} \\
\hline & $\begin{array}{l}\text { Facilities agricultural } \\
\text { area ratio(-) }\end{array}$ & \multicolumn{3}{|l|}{$\begin{array}{l}\text { The proportion of facilities } \\
\text { agricultural area in the total } \\
\text { cultivated area }\end{array}$} \\
\hline & $\begin{array}{l}\text { Multiple cropping } \\
\text { indicator }(+)\end{array}$ & \multicolumn{3}{|l|}{$\begin{array}{l}\text { Indicator of the degree of cultivated } \\
\text { land use }\end{array}$} \\
\hline & $\begin{array}{l}\text { Grain yield per unit area/ } \\
\qquad\left(\mathrm{t} / \mathrm{hm}^{2}\right)(-)\end{array}$ & \multicolumn{3}{|l|}{$\begin{array}{l}\text { The lower, the more serious the } \\
\text { impact of drought decrease yields, } \\
\text { the more sensitive to drought }\end{array}$} \\
\hline \multirow{3}{*}{$\begin{array}{c}\text { Adaptive } \\
\text { capacity (A) }\end{array}$} & $\begin{array}{c}\text { Rural electricity } \\
\text { consumption/10 } 0^{4} \mathrm{kwh}(-)\end{array}$ & $\begin{array}{l}\text { Reflect the level of the rural } \\
\text { economy, as well as the time and } \\
\text { the frequency use of agricultural } \\
\text { machinery }\end{array}$ & & \multirow{3}{*}{2010} \\
\hline & $\begin{array}{l}\text { Net income of rural } \\
\text { residents/Yuan(-) } \\
\text { Arable land per } \\
\text { capita/hm2(-) }\end{array}$ & $\begin{array}{l}\text { Income determines the drought } \\
\text { disaster recovery capabilities } \\
\text { The performance of the population } \\
\text { effect and the pressure of land }\end{array}$ & $\begin{array}{l}\text { Regional Statistical } \\
\text { Yearbook of Beijing }\end{array}$ & \\
\hline & $\begin{array}{l}\text { Agricultural power in } \\
\text { unit of arable land / ( } \\
\left.\qquad \mathrm{w} / \mathrm{hm}^{2}\right)\end{array}$ & $\begin{array}{l}\text { Manifest the level of mechanization } \\
\text { of agricultural production, but also } \\
\text { reflect the size of the irrigation } \\
\text { mechanical power during drought } \\
\text { period }\end{array}$ & & \\
\hline
\end{tabular}

Note: The table "+" and "-" represent the various evaluation and drought vulnerability positive or negative correlation (partial indicators refer to Chen Ping [29] indicator system)

\subsubsection{Indicators Quantify and Weight Calculations}

Analytic Hierarchy Process (AHP) is a method of evaluation and decision-making which is a combination of qualitative and quantitative analysis, quantitative analysis of the person's qualitative subjective judgment, making variety of heterogeneous data integration, it is a currently widely used to determine the weight. However, using AHP to build a judgment matrix will be a certain degree of subjectivity because the experts' judgment of the relative importance of the indicators varies different, while insufficient application of existing quantitative information is also an obvious inadequacy. Therefore, we can use two kinds of analytic hierarchy process method to calculate the weight of drought vulnerability indicators. Firstly, divide the evaluation behavior into three levels. Target layer is evaluation of vulnerabilities; criterion level is three drought vulnerability factors (exposure, sensitivity, adaptive capacity); lowest level is indicator layer which belonged to the upper evaluation indicators. Then, use the K-means algorithm for the discretization of each indicator data indicators, the data is divided into five levels. Finally, make assignments for each indicator positive correlation with vulnerability assigned as 2,4,6,8,10; negatively correlated with vulnerability assigned as 10,8,6,4,2.

\subsubsection{Test for Vulnerability Indicator System}

According to the daily moisture monitoring data from Beijing moisture sites in the year of 2009 to 2010 , take the moisture values during the growth of winter wheat 
from September 2009 to June 2010, use the regression kriging interpolation method to draw soil moisture distribution ArcGIS map, verify the accuracy of the indicator system through the high and low values of the moisture distribution.

\section{$3 \quad$ Results and Analysis}

Making the weight of exposure, sensitivity and adaptive capacity in the criterion level equal. Using two kinds of analytic hierarchy process method: 0 2 Three Demarcation Method and 1 9 Demarcation Method to calculate the weight of the drought vulnerability indicators. Vulnerability evaluation results of all districts and counties in Beijing are shown in Figure1 3. Using K-means algorithm to clustering exposure, sensitivity and adaptive capacity, the cluster centers are shown in Table 2.

Table 2. The cluster centers of K-means algorithm

\begin{tabular}{|c|c|c|c|c|c|c|c|c|c|c|c|}
\hline (0 2 Three & & & & & & $(1 \sim 9$ & & & & & \\
\hline Demarcation & 1 & 2 & 3 & 4 & 5 & Demarcation & 1 & 2 & 3 & 4 & 5 \\
\hline Method) Grade & & & & & & Method) Grade & & & & & \\
\hline Exposure & 1.47 & 2.02 & 2.28 & 2.32 & 2.44 & Exposure & 1.25 & 1.69 & 1.71 & 2.30 & 2.35 \\
\hline Sensitivity & 1.27 & 1.68 & 1.74 & 2.06 & 2.55 & Sensitivity & 1.64 & 1.68 & 1.87 & 1.94 & 2.17 \\
\hline $\begin{array}{l}\text { Adaptive } \\
\text { Capacity }\end{array}$ & 1.65 & 1.85 & 2.47 & 2.76 & 2.89 & $\begin{array}{l}\text { Adaptive } \\
\text { Capacity }\end{array}$ & 1.70 & 1.84 & 2.57 & 2.69 & 2.80 \\
\hline
\end{tabular}

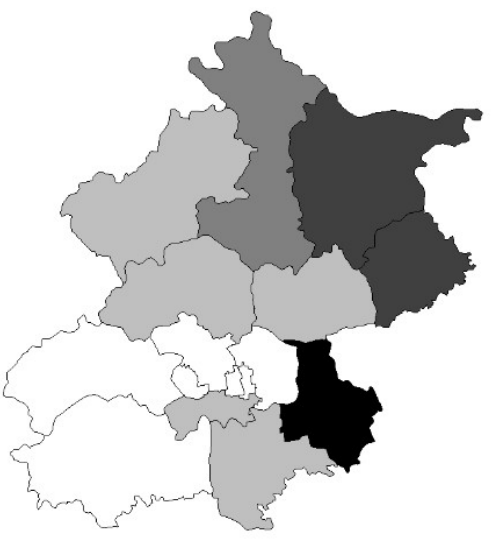

(a) 0 2 Three Demarcation Method

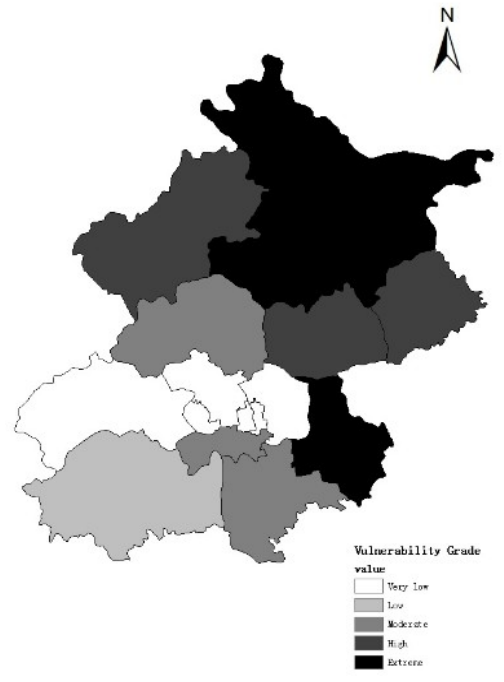

(b) 1 9 Demarcation Method

Fig. 1. Evaluation results of exposure 


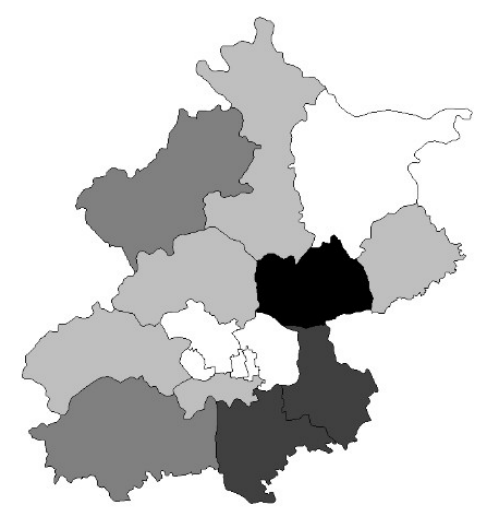

(a) 0 2 Three Demarcation Method

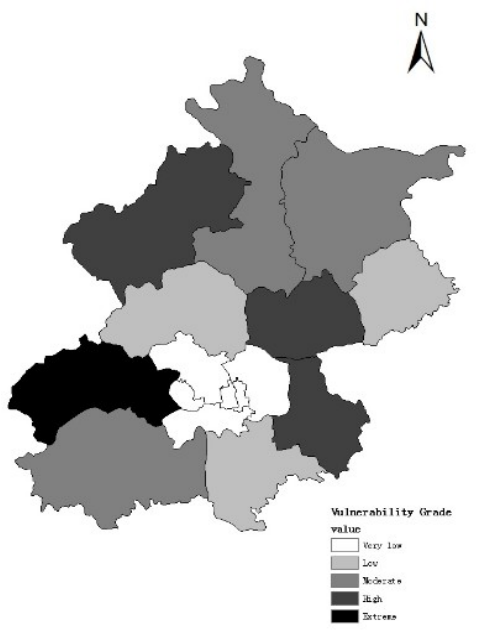

(b) 1 9 Demarcation Method

Fig. 2. Evaluation results of sensitivity

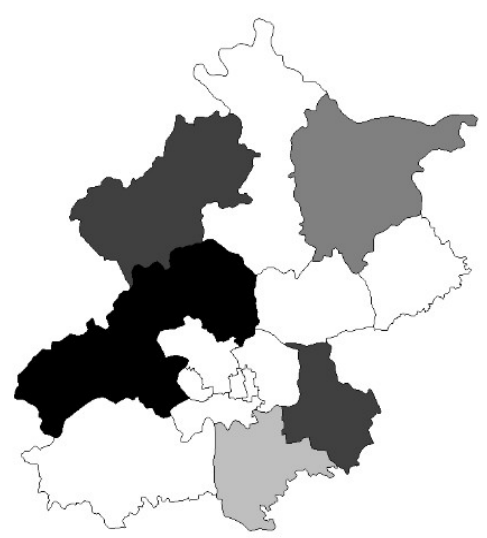

(a) 0 2 Three Demarcation Method

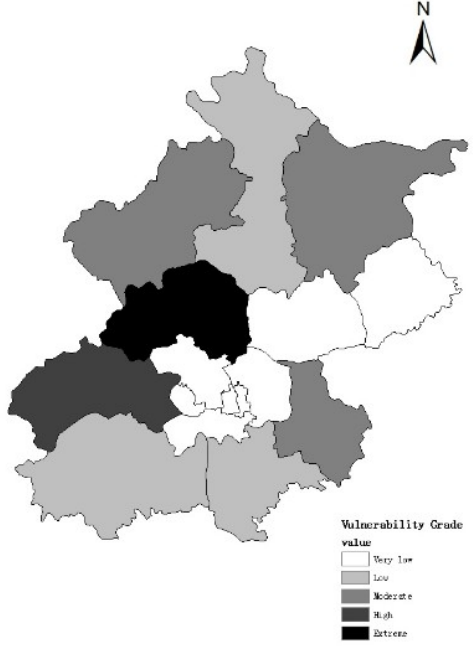

(b) 1 9 Demarcation Method

Fig. 3. Evaluation results of adaptive capacity

Beijing's topography and administrative divisions, the regression Kriging spatial interpolation on differences between evapotranspiration and precipitation are shown in Figure 4 and 5. Soil moisture site distribution of study area is shown in Figure 6, use the regression kriging interpolation method to deal with the moisture values during growth of winter wheat from September 2009 to June 2010 to draw soil moisture distribution ArcGIS map, shown as Figure 7, the level of vulnerability distribution shown in Figure 8, the distribution of soil moisture, superimposed soil moisture and adaptive capacity are shown in Figure 9and 10, respectively. 


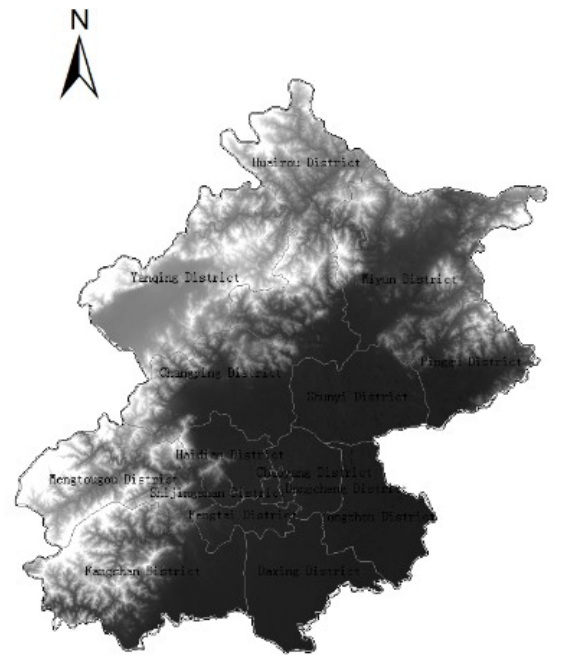

Elevation

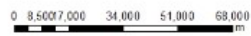

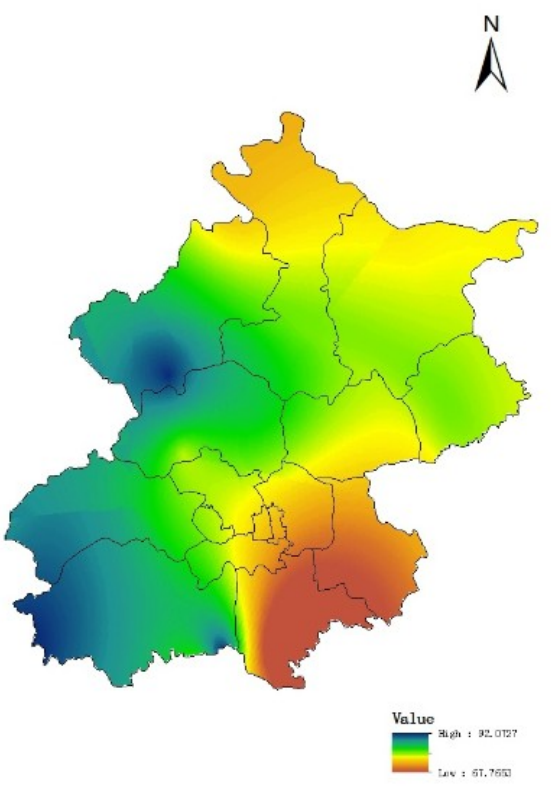

Fig. 5. Regression Kriging spatial interpolation on differences between evaporative and precipitation

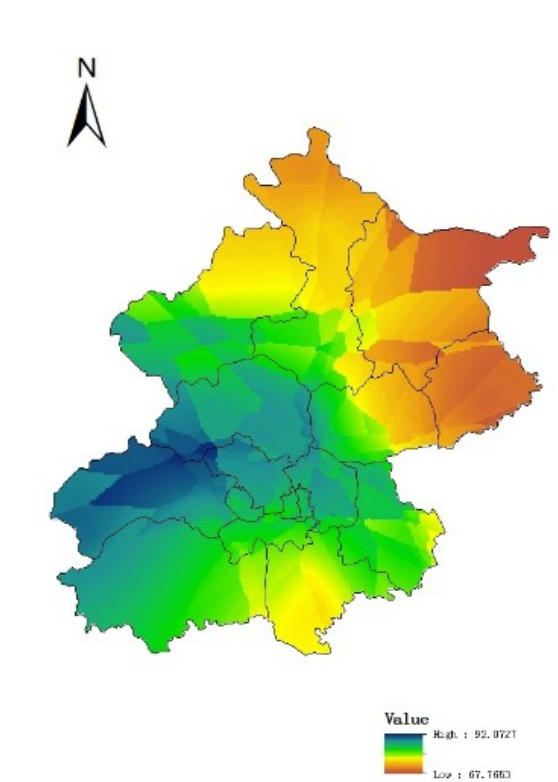

Fig. 7. Regression Kriging spatial interpolation on soil moisture
Fig. 4. Topography and administrative divisions of Beijing

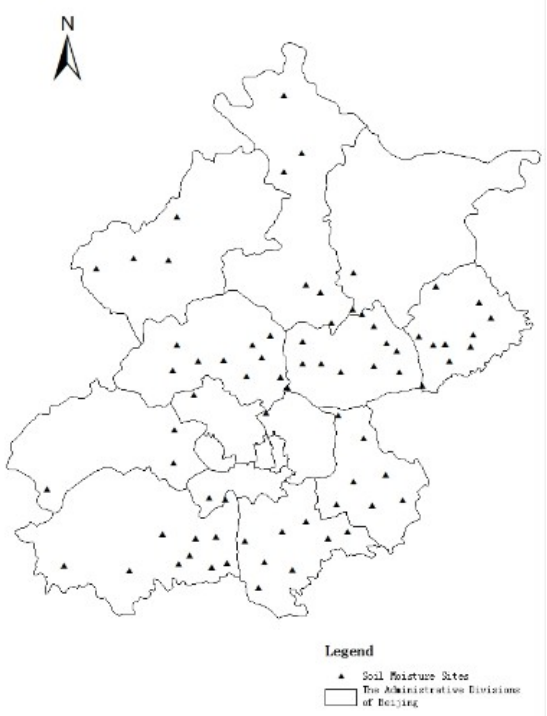

Fig. 6. Soil moisture sites in the study area 


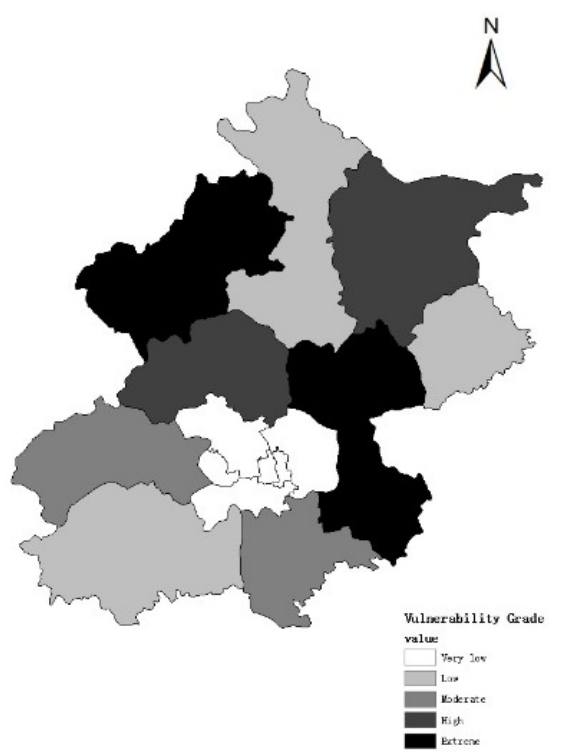

(a) 0 2 Three Demarcation Method

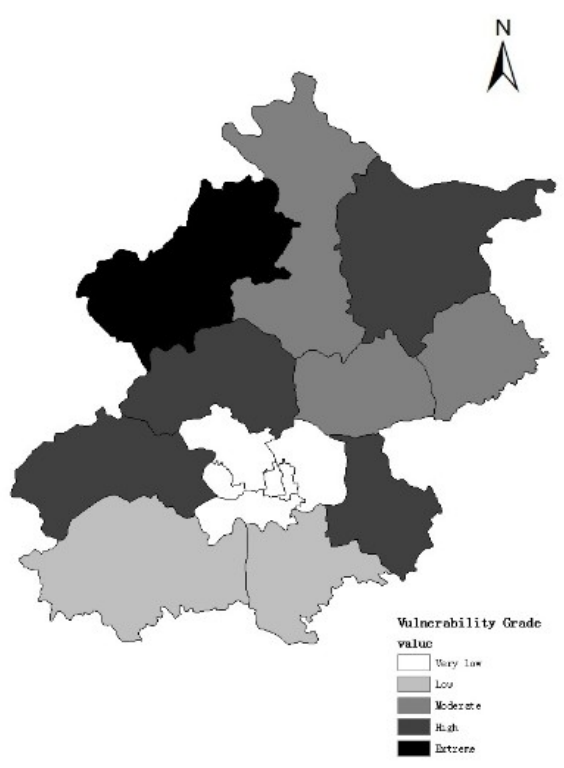

(b) 1 9 Demarcation Method

Fig. 8. The distribution of vulnerability grade
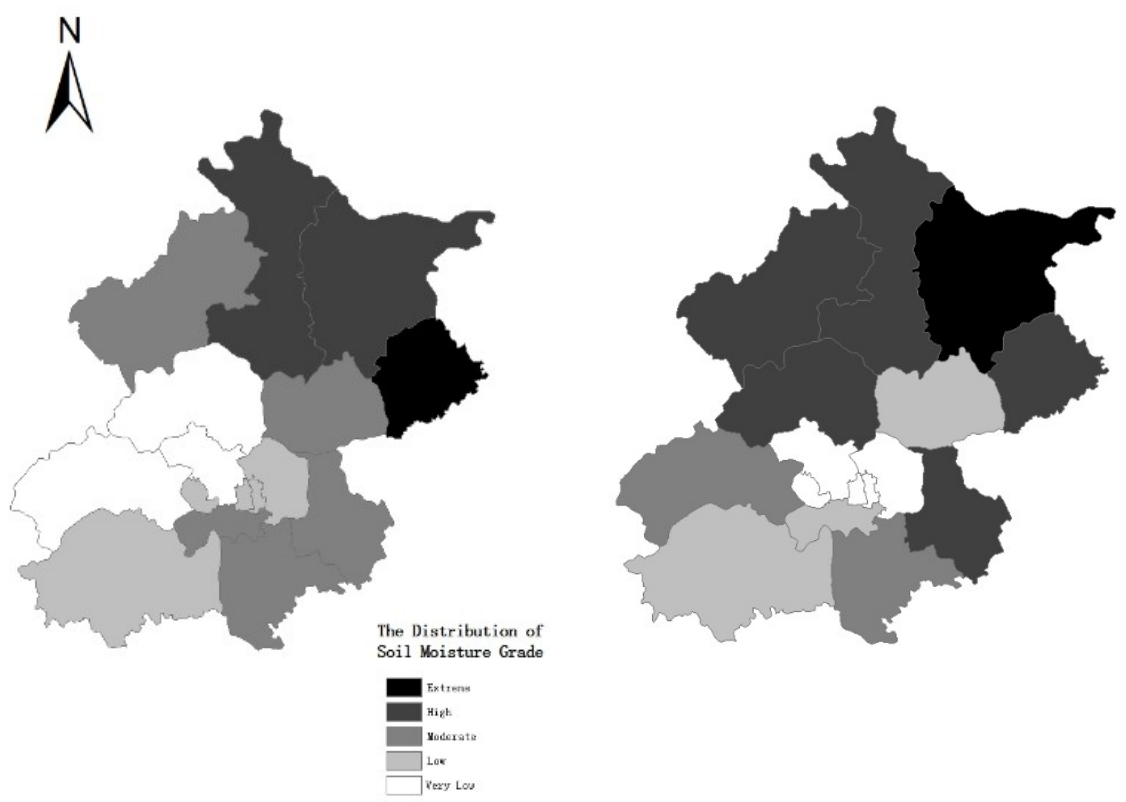

Fig. 9. The distribution of soil moisture grade
Fig. 10. The distribution of superposition of soil moisture and adaptive capacity 


\section{Discussions}

The drought vulnerability in study area varied from very low to extreme, mainly are moderate - high vulnerability. The spatial distribution of drought vulnerability (Fig.8) shows the vulnerability of the study area can be roughly considered that the mountain larger than the plains.

1) The northern and western mountains in Beijing are mainly high - extreme vulnerability. Yanqing shows extreme vulnerability, the highest level of vulnerability among all the districts and counties. Take Yanqing for example, Fig.1 show the exposure in Yanqing are Low and High. Analysis the evaluation indicators, we can find that the average elevation and average slope of Yanqing rank in the forefront of evaluation unit, the river network density is the lowest one among the study area, at the same time, the growth of winter wheat serious shortage of precipitation, $1 \sim 9$ Demarcation Method evaluation result is more accurate for it match the actual situation. Fig. 2 illustrate the sensitivity are Moderate and Extreme, and the proportion of agricultural population and the irrigation index rank in the forefront of evaluation unit, Facilities agricultural area ratio is the lowest one among the study area, sensitivity level can be higher. 1 9 Demarcation Method evaluation result is more accurate to the actual situation. Therefore, although Fig.3 describes the adaptive capacity is moderate, still not enough to reduce vulnerability of agricultural systems caused by drought exposure and drought sensitivity.

From the view of three elements of drought vulnerability, the spatial distribution of exposure shows opposite trend. The spatial distribution of exposure is closely related to the terrain conditions and crop water supply and demand situation, the exposure element in northern mountains are significantly higher than that of the western mountains, mainly for the higher elevations, steeper slopes, also the differences between evaporative and precipitation is much larger than the western mountains, the northern mountains evaluation unit experiences a large degree of drought stress. The spatial distribution of adaptive capacity mainly related to agricultural power in unit of arable land and arable land per capita, adaptive capacity in the western mountains is higher than the northern mountains in this point. The common characteristics of the High-Extreme evaluation unit is that the agricultural power in unit of arable land and arable land per capita are both very low, indicating that population pressure acting on the land is bigger in the western mountains, as well as smaller irrigation mechanical power during periods of drought. The spatial distribution rule of sensitivity has no significant; it is the combined effect of the seven factors.

2) The eastern and southern plains in Beijing are mainly low - moderate vulnerability. Tongzhou shows extreme - high vulnerability, the highest level of vulnerability among all the districts and counties. Take Tongzhou District for example, Fig.1 shows the exposure in Tongzhou is extreme. Fig. 2 represents the sensitivity is high, Fig. 3 describe the adaptive capacity are extreme and moderate, respectively. Analysis the evaluation indicators, we can find that rural electricity consumption of Tongzhou ranks in the forefront of evaluation unit, agricultural power in unit of arable land is the lowest one among the study area, Therefore, we judge 1 9 Demarcation Method evaluation result is more accurate for it match the actual situation. 
From the perspective of three elements of drought vulnerability, the spatial distribution rule of exposure, sensitivity and adaptive capacity is not obvious. In Shunyi, Tongzhou and Daxing these three areas, spatial distributions of exposure and sensitivity are more consistent, however the spatial distribution of adaptive capacity presents opposite trend, which is due to the income of rural residents is the main factor for adaptive capacity evaluation, in the southern evaluation unit, farmers generally have higher income level. When drought caused the loss of farmers, the rich farmers can easier and quicker recover from drought to pre-disaster levels. The interaction of three elements determine the vulnerability of drought in the region is mainly Low - Moderate vulnerability.

Fig.8 reflects the spatial distribution of exposure is high in northeast and low in southwest, apart from the western mountains, basically consistent with the distribution of soil moisture. The soil moisture during growth period of winter wheat, has taken irrigation conditions into account at this stage, considers the exposure and sensitivity of vulnerability, and does not involve the adaptive capacity. Thus, we can make the following assumptions: the distribution of vulnerability is the superposition of soil moisture and adaptive capacity.

Averaging and Superimposing soil moisture grade (Fig.9) and adaptive capacity grade to make the Fig.10, compared result with 1 $\sim 9$ Demarcation Method evaluation result, the superposition effect of the southern is better than the northern, in the southern except a small number of a grade difference, the rest are the same. However, in the north region except for a few results are the same, the rest several areas have one grade difference. That describes the northern region influence largely by the sensitivity factors. Therefore, regions or districts that its agricultural system elements susceptible to the effects of drought should consider the interaction of three elements of vulnerability.

\section{Conclusions}

In this study, make crop water demand and supply as an evaluation indicator of drought exposure, focus on the balance between water demand and supply while considering other factors, for example, natural, social and economic factors that influence the process of drought disaster. Try to use soil moisture to examine the results of the evaluation; the method is more accurate reflection of the potential losses of drought on different evaluation unit.

However, using AHP to build a judgment matrix will be a certain degree of subjectivity because the experts' judgment of the relative importance of the indicators varies different, while insufficient application of existing quantitative information is also an obvious inadequacy. When using the two kinds of analytic hierarchy process method to calculate the weight of drought vulnerability indicators, can avoid judgment matrix randomness which varies from person to person. This method is more objectivity. Compared the two results from 0 2 Three Demarcation Method and $1 \sim 9$ Demarcation Method, the evaluation result of $1 \sim 9$ Demarcation Method is more accurate for it match the actual situation. 
Using K-means algorithm to making indicator data discretization, can avoid the disadvantages of equal-width interval method which is too simple and easily influenced by the amount of data. Indicator data discretization has directly impact on the assignment of the indicator data and the accuracy of the final vulnerability assessment. Therefore, a suitable discretization method is particularly important.

Drought vulnerability is the result of interaction of the three elements: exposure, sensitivity, and adaptive capacity. These three elements have its own rule in the spatial distribution. Single soil moisture distribution is an important factor that influences exposure, while having some impact on sensitivity, which lacks the element of adaptive capacity. In the development of drought-prevention policy, combining soil moisture and adaptability to determine drought risk can be used as a simple method for evaluation, however, areas or regions which affected largely by sensitivity should also take full account of the interaction of the three elements, and make it a starting point to develop the corresponding drought policy. Prevent or reduce disaster losses before the drought had occurred.

\section{References}

1. Brooks, N., Neil Adger, W., Mick Kelly, P.: The determinants of vulnerability and adaptive capacity at the national level and the implications for adaptation. Global Environmental Change 15(2), 151-163 (2005)

2. Lindner, M., Maroschek, M., Netherer, S., et al.: Climate change impacts, adaptive capacity, and vulnerability of European forest ecosystems. Forest Ecology and Management 259(4), 698-709 (2010)

3. Copeland, H.E., Tessman, S.A., Girvetz, E.H., et al.: A geospatial assessment on the distribution, condition, and vulnerability of Wyoming's wetlands. Ecological Indicators 10(4), 869-879 (2010)

4. Yu, C., Hao, Z.: Quantitative Assessment Research of Water Resources System Vulnerability of Shanxi Province: Bioinformatics and Biomedical Engineering. In: 3rd International Conference on ICBBE 2009. IEEE (2009)

5. Turner, B.L., Matson, P.A., McCarthy, J.J., et al.: Illustrating the coupled humanenvironment system for vulnerability analysis: three case studies. Proceedings of the National Academy of Sciences 100(14), 8080-8085 (2003)

6. Füssel, H.: Vulnerability: a generally applicable conceptual framework for climate change research. Global Environmental Change 17(2), 155-167 (2007)

7. Xu, W., Ren, X., Smith, A.: Remote sensing, crop yield estimation and agricultural vulnerability assessment: A case of Southern Alberta: Geoinformatics. In: 2011 19th International Conference on IEEE (2011)

8. Wilhelmi, O.V., Wilhite, D.A.: Assessing vulnerability to agricultural drought: a Nebraska case study. Natural Hazards 25(1), 37-58 (2002)

9. Wu, H., Wilhite, D.A.: An operational agricultural drought risk assessment model for Nebraska. Natural Hazards 33(1), 1-21 (2004)

10. Simelton, E., Fraser, E.D.G., Termansen, M., et al.: Typologies of crop-drought vulnerability: an empirical analysis of the socio-economic factors that influence the sensitivity and resilience to drought of three major food crops in China (1961-2001). Environmental Science \& Policy 12(4), 438-452 (2009)

11. Fontaine, M.M., Steinemann, A.C.: Assessing vulnerability to natural hazards: impactbased method and application to drought in Washington State. Natural Hazards Review 10(1), 11-18 (2009) 
12. Parry, M.L., Canziani, O.F., Palutikof, J.P., et al.: Climate change 2007: impacts, adaptation and vulnerability. Intergovernmental Panel on Climate Change (2007)

13. Polsky, C., Neff, R., Yarnal, B.: Building comparable global change vulnerability assessments: the vulnerability scoping diagram. Global Environmental Change 17(3), 472485 (2007)

14. Metzger, M.J., Leemans, R., Schröter, D.: A multidisciplinary multi-scale framework for assessing vulnerabilities to global change. International Journal of Applied Earth Observation and Geoinformation 7(4), 253-267 (2005)

15. Turner, B.L., Kasperson, R.E., Matson, P.A., et al.: A framework for vulnerability analysis in sustainability science. Proceedings of the National Academy of Sciences 100(14), 80748079 (2003)

16. Rashed, T., Weeks, J.: Assessing vulnerability to earthquake hazards through spatial multicriteria analysis of urban areas. International Journal of Geographical Information Science 17(6), 547-576 (2003)

17. Shouyu, C., Yu, G.: Variable fuzzy sets and its application in comprehensive risk evaluation for flood-control engineering system. Fuzzy Optimization and Decision Making 5(2), 153-162 (2006)

18. Apel, H., Thieken, A.H., Merz, B., et al.: Flood risk assessment and associated uncertainty. Natural Hazards and Earth System Science 4(2), 295-308 (2004)

19. Zou, Q., Zhou, J., Zhou, C., et al.: Comprehensive flood risk assessment based on set pair analysis-variable fuzzy sets model and fuzzy AHP. Stochastic Environmental Research and Risk Assessment 27(2), 525-546 (2013)

20. Huang, D., Zhang, R., Huo, Z., et al.: An assessment of multidimensional flood vulnerability at the provincial scale in China based on the DEA method. Natural hazards 64(2), 1575-1586 (2012)

21. Metzger, M.J., Rounsevell, M., Acosta-Michlik, L., et al.: The vulnerability of ecosystem services to land use change. Agriculture, Ecosystems \& Environment 114(1), 69-85 (2006)

22. Blaikie, P.M.: At risk: natural hazards, people's vulnerability, and disasters. Psychology Press (1994)

23. Adger, W.N., Kelly, P.M.: Social vulnerability to climate change and the architecture of entitlements. Mitigation and Adaptation Strategies for Global Change 4(3-4), 253-266 (1999)

24. Luers, A.L.: The surface of vulnerability: an analytical framework for examining environmental change. Global Environmental Change 15(3), 214-223 (2005)

25. Keyantash, J., Dracup, J.A.: The quantification of drought: an evaluation of drought indices. Bulletin of the American Meteorological Society 83(8), 1167-1180 (2002)

26. Wilhelmi, O.V., Wilhite, D.A.: Assessing vulnerability to agricultural drought: A Nebraska case study. Natural Hazards 25(1), 37-58 (2002)

27. Fekete, A., Damm, M., Birkmann, J.: Scales as a challenge for vulnerability assessment. Natural Hazards 55(3), 729-747 (2010)

28. Antwi-Agyei, P., Fraser, E.D., Dougill, A.J., et al.: Mapping the vulnerability of crop production to drought in Ghana using rainfall, yield and socioeconomic data. Applied Gegraphy 32(2), 324-334 (2012)

29. Ping, C., Xiaoling, C.: Evaluating drought vulnerability of agricultural system in Poyang Lake Ecological Economic Zone,China. Transactions of the CSAE 27(8), 8-13 (2011) (in Chinese with English abstract)

30. Huang, J., Liu, Y.: The assessment of regional vulnerability to natural hazards in China: World Automation Congress (WAC). IEEE (2012) 